\title{
PReS-FINAL-2272: Association of benign joint hypermobility syndrome with mitral valve prolapsed in Iranian children
}

\author{
R Shiari ${ }^{i^{*}}$, F Vaziri ${ }^{2}$, E Zahmatkesh ${ }^{2}, \mathrm{H}$ Javaherizadeh $^{3}$ \\ From 20th Pediatric Rheumatology European Society (PReS) Congress \\ Ljubljana, Slovenia. 25-29 September 2013
}

\section{Introduction}

Benign joint hypermobility syndrome (BJHS) is a clinical condition characterized by an increased ability of joints during passive and dynamic movements. Mitral valve prolapsed (MVP) is the most commonly diagnosed cardiac abnormality and affects around $5 \%$ of population. Abnormalities of collagen have been found in valves of patients with MVP.

\section{Objectives}

There were limited published papers concerning children with BJHS and MVP. The aim of this study was to determine the association of BJHS with mitral valve prolapsed in children.

\section{Methods}

Sixty-three children with benign joint hypermobility syndrome were included in case group and 63 without any rheumatologic disease were placed in control group. We used Carter-Wilkinson and Beighton criteria for diagnosing of benign joint hypermobility syndrome. MVP was evaluated by echocardiography in both groups. The mitral leaflet displacement $>2 \mathrm{~mm}$ considered as cut off for diagnosis of MVP.

\section{Results}

In this study, 32 girls and 31 boys were included. Mean of age in case group was 7.1 was $6.9(p=0.001)$. Mitral valve prolapse was significantly higher among cases with BJHS aged $>7$ (58.8\%) year compared to $3-7$ (41.2\%) year of age $(\mathrm{p}=0.027)$. Heart murmur and palpitation was more common among children with benign joint hypermobility syndrome with MVP compared to children without MVP $(\mathrm{p}<0.05)$.

\section{Conclusion}

The incidence of MVP among children with benign joint hypermobility was significantly higher than control group.

\section{Disclosure of interest}

None declared.

\section{Authors' details}

${ }^{1}$ Pediatric Rheumatology, Shahid Beheshti University of Medical Sciences, Mofid Children's Hospital, Tehran, Iran, Islamic Republic Of. Pediatrics, Shahid Beheshti University of Medical Sciences, Tehran, Iran, Islamic Republic Of. ${ }^{3}$ Pediatrics, Ahvaz Jundishapur University, Tehran, Iran, Islamic Republic Of.

Published: 5 December 2013

doi:10.1186/1546-0096-11-S2-P262

Cite this article as: Shiari et al:: PReS-FINAL-2272: Association of benign joint hypermobility syndrome with mitral valve prolapsed in Iranian children. Pediatric Rheumatology 2013 11(Suppl 2):P262. 